\title{
Bundesgerichtsentscheid zugunsten der Selbstdispensation
}

\section{Sven Bradke}

Geschäftsführer der Ärzte mit Patientenapotheke (APA)

* Urteil vom 23. September 2011 der II. öffentlichrechtlichen Abteilung, BGE 2C_53/2009.

Korrespondenz:

Dr. rer. publ. HSG Sven Bradke Geschäftsführer der Ärzte mit Patientenapotheke (APA) Röschstrasse 18

CH-9006 St. Gallen

Tel. 0712465140

info[at]patientenapotheke.ch
Am 23. September fällte die II. öffentlich-rechtliche Abteilung des Bundesgerichts in Lausanne ein langersehntes Urteil.* Zur Debatte stand, ob die angenommene Zürcher Volksinitiative «JA zur Wahlfreiheit beim Medikamentenbezug» vom 30. November 2008 rechtens sei oder nicht. Zur Erinnerung: Das Volk entschied damals, dass grundsätzlich auch in Arztpraxen der Städte Winterthur und Zürich Medikamente an Patienten abgegeben werden dürften, sofern diese dies wünschten.

\section{SD: Verstoss gegen Bundesrecht?}

Neben formellen Beschwerden von Privaten reichten die Apothekerverbände des Kantons und der Städte Zürich und Winterthur beim Bundesgericht eine materielle Beschwerde gegen die Abstimmung ein. Und zwar mit dem Inhalt, der neue Gesetzestext sei nicht in Kraft zu setzen, da dieser den Umsatz der gesamten Apothekerschaft im Kanton verringern würde. Er verstosse zudem gegen Bundesrecht, namentlich gegen das Krankenversicherungsgesetz (Art. 37 Abs. 3), das Heilmittelgesetz (Art. 24 und 30), das Medizinalberufegesetz sowie gegen die Eigentumsgarantie und die Wirtschaftsfreiheit.

\section{In allen Punkten unbegründet}

Das Bundesgericht anerkannte die Beschwerdeberechtigung der Apotheker, verneinte aber alle vorgebrachten Argumente. Es wies die Beschwerde als in allen Punkten unbegründet zurück. In der mündlichen Beratung wurde zudem nur über den Artikel 37 Abs. 3 KVG diskutiert. Eine Minderheitsmeinung forderte aufgrund einer Beurteilung der parlamentarischen Beratung, dass die Kantone spezielle Massnahmen zum Schutz der Zugangsmöglichkeiten der Patienten zu einer Apotheke treffen müssten. Eine Mehrheitsmeinung kam bei derselben Beurteilung zum Schluss, dass die Kantone frei entscheiden könnten, welches Abgabesystem gelten soll. Der letzte Satz des Artikels 37 Abs. 3 KVG zur Zugangsmöglichkeit der Patienten zu einer Apotheke sei rein programmlicher Natur und gelte höchstens im Sinne einer Richtungsweisung. So, wie der Bundesrat dies auch beurteile. Ein strukturpolitischer Schutz der Apotheker sei nicht der Wille des Gesetzgebers gewesen.

\section{Ärztliche Medikamentenabgabe im Notfall und im Alltag}

Das Bundesgericht stellte auch einen Verstoss der Zürcher Regelung gegen das Heilmittelgesetz und das Medizinalberufegesetz in Abrede. Es hielt fest, dass Ärzte aufgrund ihrer Ausbildung in der Lage seien, Medikamente abzugeben. Und zwar nicht zuletzt deshalb, weil sie auch in Notfällen für die nötige und richtige Behandlung der Patienten mit Medikamenten sorgten. Ein grundsätzliches Verbot der Selbstdispensation sei zudem höchstens über eine eindeutige gesetzliche Regelung möglich. Eine solche bestehe aber nicht.

\section{Stärkung der Selbstdispensation}

Dieses langerwartete Urteil stärkt die rechtliche Position der Selbstdispensation in verschiedener Hinsicht. Erstens bestätigt und festigt es die bisherige Auslegungspraxis des Bundesgerichts, wonach die Kantone frei entscheiden können, welches Abgabesystem sie für geeignet ansehen. Zweitens widerspricht es den oft zu hörenden Vorstellungen, dass Apotheken strukturpolitisch geschützt werden müssten. Drittens lehnt es alle weiteren Argumente wie beispielsweise jenes einer ungenügenden Ausbildung der Ärzte im Bereich der Medikamente ab. Viertens betont es, dass nur eine eindeutige gesetzliche Regelung ein allfälliges Verbot der Selbstdispensation begründen könnte. Folglich gilt es seitens der Ärzteschaft, darauf zu achten, dass keine solchen Regelungen in Bundesgesetze einfliessen.

\section{Kantonale Autonomie bestätigt}

Für die Kantone bedeutet dieses höchstrichterliche Urteil, dass bei Revisionen der Gesundheitsgesetze keine Diskussionen geführt werden müssen, was bezüglich der Selbstdispensation zulässig ist und was nicht. Die Kantone haben die föderale Autonomie, jene Regelung vorzusehen, die sie für richtig ansehen. Nach all den Jahren des Kampfes haben wir somit heute zumindest ein klares Urteil auf dem Tisch.
Das Bundesgericht bestätigt, dass Ärzte in der Praxis Medikamente abgeben dürfen.

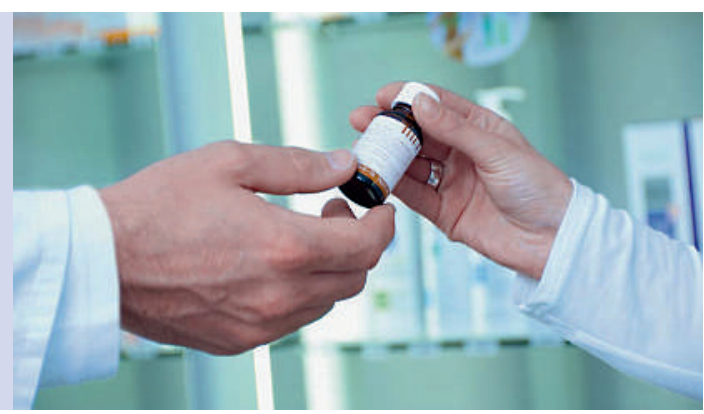

